\title{
25 Research Square \\ Sex Differences of the Brain Structural Adaptation to Hypoxic Environment
}

\section{Cunxiu Fan}

Xiamen Huaxia University

\section{Cunhua Zhao}

Medical College of Xizang University

\section{Yuhua Zhao}

Tibet Autonomous Region People's Hospital

\section{Wu Yin}

Tibet Autounomous Region People's Hospital

Jianzhong Lin

Xiamen University

Jiaxing Zhang ( $\nabla$ zhangjiaxing@xmu.edu.cn )

Medical College of Xiamen University https://orcid.org/0000-0003-0452-1885

\section{Research article}

Keywords: Brain, High altitude, Gray matter, MRI, Sex differences

Posted Date: August 31st, 2019

DOl: https://doi.org/10.21203/rs.2.13727/v1

License: (c) (i) This work is licensed under a Creative Commons Attribution 4.0 International License.

Read Full License 


\section{Abstract}

Background Different physiological and pathological patterns have been found in the two sexes at high altitude. However, sex differences in brain remain unknown. Methods T1-weighted MRI scanned in 61 Tibetan males and 68 Tibetan females aged 17-23, and Freesurfer was used to detect brain structures. Neuropsychological tests were also performed. One hundred and twenty-seven matched lowland Han subjects were controls. Results Both Tibetan and Han males had larger global gray matter (GM) volume and white matter volume than females, while Tibetan but not Han female brains contained a larger proportion of GM than male brains. Tibetan females had significant smaller regional GM volume in the left rostral middle frontal gyrus, pars opercularis, and right caudal middle frontal gyrus and moreover, GM volume in the left pars opercularis positively correlated with performance in digit span. However, Tibetans females had significantly thicker cortices in the left rostral middle frontal gyrus, left pars triangularis, right rostral middle frontal gyrus, and right pars triangularis than males and cortical thickness in these regions negatively correlated with altitude. In Tibetan females but not males, the negative correlation of cortical thickness with altitude has been testified by global analysis. Conversely, Han subjects showed discrepant sex differences in brains with Tibetans, showing larger regional GM volume and thicker cortices in different brain areas. Conclusion Sex differences exist between Tibetan and Han brains. Female brains may be more susceptible to hypoxia. Sex differences in the brains of Tibetans may be related to different neuropsychiatric performances in the two sexes.

\section{Background}

Different adaptation patterns have been found in the two sexes exposed to high-altitude (HA) environment. Females were thought to cope better with hypoxia than males due to higher hypoxic ventilation response [1]. At HA, females have lower hemoglobin levels [2], less nocturnal periodic breathing [3, 4], and less fat mass loss [5] and higher systolic and diastolic pressures [6] than males. Moreover, although showing greater incidence of acute mountain sickness, females have lower risk of chronic mountain sickness than males [7-9].

Sex-based differences of brain functions in response to stress have been reported [10-12]. Hypoxic stress is the dominant environmental factors at HA. The brain is one of the heaviest consumers of oxygen in the body and thus is inevitably suffered from hypoxia. There is evidence that sex influences all levels of brains in extension of brain damage, mechanisms of damages, behavioral outcome, and treatment efficacy in the neonatal hypoxic-ischaemic models [13-15]. Sex-specific cerebral cortices, moleculars, density of nerve cells, neuroplasticity, iron content, and cerebral hemodynamic values changes were also found in hypoxic populations [16-18]. Clinical data and animal studies confirmed sex differences in hypoxic-ischaemic outcomes, including emotion [19-21], cognitions [22], and attention domains. Females have better neurological outcome after traumatic brain injury [23, 24]. Sex differences have also been reported in protection of the brain after posthypoxic hypothermia [25] and poly polymerase-1 knockout [26]. Moreover, sex differences in brain energy metabolism have been demonstrated in animal models of 
neonatal hypoxia-ischemia [27]. Altogether, these studies suggested that females were more susceptible to hypoxia.

A lot of documents have revealed sex differences in the brain architecture at normoxic environment. The most consistent observations are that males have larger global brain volumes than females [28], while female brains contain a larger proportion of gray matter than male brains [29, 30]. However, sex differences in gray matter (GM) volume have been reported to be variable in the literature. In different studies, males showed larger regional GM volume in a large number of brain regions, including the amygdala, hippocampus, anterior parahippocampal gyrus, precuneus, putamen, temporal pole, and posterior and anterior cingulate cortices. On the contrary, females showed larger regional GM volume in the frontal pole, inferior and middle frontal gyri, pars triangularis, parietal operculum, anterior cingulate cortex, insular cortex, Heschl's gyrus, parahippocampal gyrus, lateral occipital cortex, and thalamus and precuneus $[28,31]$. Sex differences in cortical thickness (CT) have also been reported to be inconsistent and cover a large number of brain regions. Females have thicker cortices than males in the superior and inferior frontal gyri, superior parietal gyrus, and postcentral gyrus, parietal lobe, and superior and posterior temporal gyri [32-34]. In addition, a study showed males had thicker temporal and frontal cortices than females [35].

Based on the above data, we hypothesized that hypoxia exposure could also have differently exerted its effects on male and female brain developments, and thus sex differences of brains in HA natives could be discrepant with that in lowland residents. For this purpose, Tibetan college students, who were born and raised on the Qinghai-Tibetan Plateau, were recruited in the present study. In addition, Han college students at lowlands were recruited as controls.

\section{Methods}

\section{Subjects}

Sixty-one male and 68 Tibetan females (freshmen or sophomore) were recruited from Xizang University at Lasa $(3650 \mathrm{~m})$. They originally lived at altitude of 3119-4642 $\mathrm{m}$ on the Qinghai-Tibetan Plateau. Their ancestors are all native Tibetans, and these students were born and raised at HA without any prior descent to lowlands or ascent to higher altitudes. The information of subjects was shown in Table 1. In addition, 73 healthy female and 54 male Han college students (male: $19.9 \pm 1.9$; female: $19.2 \pm 1.8$ ), who have been living at lowlands ( $<500 \mathrm{~m}$ ), were recruited from Xiamen University at Xiamen, China as controls. Male and female students do not differ in college enrollment scores. All subjects were not smokers, and were excluded if they had a past history of mountain sickness, neurological disorder, or head injury. Procedures were fully explained, and all subjects provided written informed consent before participating in the study. The experimental protocol was approved by the Research Ethics Review Board of Xiamen University. 


\section{Neuropsychological tests}

Subjects were given the following tests: (1) The Chinese revised version of Wechsler Memory Scale provided measures visual and verbal memory functions; (2) Rey-Osterrieth Complex Figure (ROCF) assessed short- and long-term visual memory and visuoconstructional ability. The procedures of the above tests have been described in our previous study [70]. (3) Beck Anxiety Inventory assessed the severity of anxiety.

\section{MRI data acquisition}

Brain images were obtained on two Tim Trio 3T scanners (Siemens, Erlangen, Germany). Tibetans were scanned at the MRI Center in Tibet Autonomous Region People's Hospital, Lasa, China, and Han subjects were scanned at the MR Imaging Center, First Affiliated Hospital of Xiamen University, Xiamen, China. A 3D structural MRI was acquired using a T1-weighted MPRAGE sequence: TR/TE $=5000 / 298 \mathrm{~ms}$, FOV $=$ $240 \times 256 \mathrm{~mm}^{2}$, average $=1$, matrix $=256 \times 240$, voxel size $=1 \times 1 \times 1 \mathrm{~mm}^{3}$, slice thickness $=1 \mathrm{~mm}$. Conventional 2D T1 and T2 images were also acquired for any incidental findings. The data analysis was conducted by two researchers who were blind to the status of the subjects.

\section{FreeSurfer analysis}

FreeSurfer (version 510; http://surfer.nmr.mgh.harvard.edu) was used for analyses of CT and cortical GM volume. The process consisted of removal of non-brain tissue, mapping to Talairach-like space, and segmentation of the GM-white matter (WM) and pial boundaries. These maps of measurements were obtained by reconstructing representations of the GM/WM boundary and the white boundary to the $\mathrm{GM} /$ cerebrospinal fluid boundary and then calculating the closest distance from those surfaces at each vertex on the tessellated surfaces. Areal maps obtained here were along with the methods described by Joyner et al. [71] and Palaniyappan et al. [72]. All subjects' images were resampled to the FreeSurfer default common surface template using a high-resolution surface-based averaging technique that aligned cortical folding patterns. Finally, the surface data were spatial smoothed using a Gaussian kernel of $8 \mathrm{~mm}$ full-width at half-maximum.

GM volume, WM volume, and CT were compared using Independent t-test, with age as covariates. Moreover, for GM and WM volumes analyses, we also test the sex differences using intracranial volume as covariate. The statistical parametric map was generated at $p<0.05$ (FDR corrected for multiple comparisons).

\section{Statistical analysis of demographic variables}


Data were analyzed using SPSS19.0. Independent $t$ test was used to measure between-group neuropsychological differences. Statistical significance was set at $p<0.05$.

To analyze the correlations of GM volume and CT values with altitude and neuropsychological behaviors, the GM volume and CT values were extracted from each individual's normalized maps. Moreover, the global correlations of CT with altitude were also analyzed. The correlations were analyzed using SPSS. Statistical significance was set at $p<0.05$, with age and education as covariates.

\section{Results}

\section{Neuropsychiatric characteristics}

Neuropsychiatric characteristics of HA Tibetans are showed in Table 2. There were higher scores in Wechsler Memory Scale subset tests (digit serial accumulation and forward digit span) in males than females.

\section{Global brain volume}

Tibetan males had significantly larger global GM volume $(p<0.001)$ and global WM volume $(p<0.001)$ than females, (Fig. 1A). However, Tibetan female brains contained a larger proportion of GM volume than males $(p=0.043)$ (Fig. 1B).

Han males had significantly larger global GM volume $(p<0.001)$ and global WM volume than females $(p$ $<0.001$ ) (Fig. 1C). No significant difference in proportion of GM volume between males and females was detected (Fig. 1D).

\section{Regional cortical GM volume}

Tibetans females had significant smaller regional GM volume in the left rostral middle frontal gyrus, pars opercularis, and right caudal middle frontal gyrus than males (Fig. 2). There was no significantly larger cortical GM volume in females than males.

Han females had significantly larger regional GM volume in the right precentral gyrus and left postcentral gyrus than males (Fig. 2).

GM volume in the left pars opercularis in Tibetan males and females had a significant positive correlation with forward digit span scores (Fig. 3).

\section{Regional CT}


Tibetans females had significantly thicker cortices in the left rostral middle frontal gyrus, left pars triangularis, right rostral middle frontal gyrus, and right pars triangularis than males (Fig. 4). There was no significantly thicker cortex in males than females.

Han females had significantly thicker cortices in the left lateral occipital cortex, precentral cortex, superior frontal gyrus, and rostral middle frontal gyrus as well as right lateral occipital cortex and superiortemporal gyrus than males (Fig. 4).

In Tibetan females, CT values in the left rostral middle frontal gyrus, left pars triangularis, right rostral middle frontal gyrus, and right pars triangularis had significant negative correlations with altitude (Fig. 5). No significant correlations between CT values and altitude existed in Tibetan males.

\section{Global analysis of CT with altitude}

Global analysis showed that, in Tibetan females, CT had negative correlation with altitude in the right lateral orbitofrontal gyrus, caudal middle frontal gyrus, and inferior parietal cortex and the left medial orbitofrontal gyrus, superior parietal cortex, superior frontal gyrus, and pars triangularis (all $p<0.05$ ) (Fig. 6). There were no significant correlations between CT values and altitude in Tibetan males.

\section{Discussion}

Our study revealed that Tibetan males had larger brains than Tibetan females in both global GM volume and WM volume, which was consistent with that found in lowlanders such as Germany, American, Korean, Swiss, and Australian [28] as well as in our present Chinese Han subjects. Tibetan females had a larger proportion of GM volume than males, which was also found in previous studies on lowlanders [29, 30] but not in our present study on Han subjects. Moreover, Tibetan females had smaller regional cortical GM volume than males, with GM volume in the left pars opercularis in males and females had a significant positive correlation with forward digit span performance. In contrast, Tibetan females had larger regional CT than males and moreover, in females, CT values in these regions had significant negative correlations with altitude.

In our study, the accurate brain sites showing sex differences of CT were different between Tibetans and Han subjects, but they were all within the regions found in Germany aged $24.3 \pm 4.3$ years [36], in Korean females aged 19-36 years [32], and in American aged 7-87 years [33], with significantly thicker cortices in females. In our study, although we got an opposite results in regional GM volume between Tibetans and Han, but the smaller regions in Tibetan females and the larger regions in Han females all overlapped and were consistent with the regions found in Germany aged 20-30 years [37]. In addition, the regions that showing higher $\mathrm{CT}$ in the right superior temporal gyrus and left occipital lobe in our Han subjects also showed larger GM volume in America females aged $25.1 \pm 4.5$ years [38]. In the present study, we have also analyzed brain structural differences between Han males and Tibetan males and brain structural 
differences between Han females and Tibetan females, and the results showed that the sex differences of brains were consistent with that found in our previous study in Tibetans and Han subjects [39].

Our study found that Tibetans females had significantly thicker regional cortical thickness than males and the correlation of regional CT with altitude existed in female but not male Tibetans by both regional and global analyses. (1) Firstly, these results suggest that HA environmental factors may affect easily on brain developments in female residents. In agreement with our results, depression and anxiety behaviors have been observed to increase with altitude of housing in female, but not male rats [21]. In our previous study on sea-level residents after 4-week exposure at Qinghai-Tibet Plateau, both males and females showed significant differences in cerebral iron concentrations in deep gray matters in the brains after the HA stay, while the increased proportion of females (4\%) was greater than males (2\%) [17]. Baum et al. [40] found that chronic intermittent hypoxia induced a higher Fosb gene expression in females than in males, reflecting stronger neuroplastic dynamics. (2) Secondly, these results suggest that females may have a better capacity to adapt to hypoxia. Some clinic and experimental data support this suggestion. When both male and female rats were reared at an altitude, red blood cell count, haematocrit, and plasma erythropoietin levels were lower in females than in males [41]. A lot of studies showed that female animals with cerebral hypoxia-ischemia were less adversely affected relative to comparably injured males $[14,22,42]$. Clinical data also suggests females with cerebral hypoxia-ischemia exhibited less severe behavioral deficits compared to males [19]. Charriaut-Marlangue et al. [43] reviewed that cohort studies have demonstrated a higher vulnerability in males towards neonatal ischemic and/or hypoxic-ischemic injury. Compared with female brains, male brains were poorly repaired after neonatal hypoxia-ischemia, and males have an increased incidence of long-term cognitive deficits. Female resistance to hypoxia can explain the lower female total mortality rate in infancy, childhood and adulthood [44].

The greater capacity for females to adapt to hypoxia may be related to the effects of circulating estrogen and progesterone. This two hormones have been shown greater in females living at HA than females who resident at lowlands [45]. It has been shown that the resistance of females to ischemia is acquired after puberty [46] and is lost after menopause, which is in accordance with the protective effects of estrogen [47]. Exogenous administration of estrogen has been shown to reduce ischemia-induced cerebral injury [47], and the protective effects may be through preventing neuron death [48] and related to its antioxidant properties [49]. Estrogen can also increase regional CBF [50-52] and correlates directly with CBF velocity [53]. Females have higher CBF compared with males in the left inferior frontal gyrus, bilateral middle temporal gyri, and left superior temporal gyrus $[54,55]$. In addition, in animal models of neonatal hypoxiaischemia, males are more sensitive to mitochondrial dysfunction, with increased mitochondrial permeability on the inner and outer membranes leading to a high amount of released proteins as compared to females [27]. Taken together, the increased blood sex hormones, increased CBF, and relatively little mitochondrial permeability may contribute to female resistance to hypoxia. Females also have a better capacity to adapt to cold. For example, the vascular response to coldness at HA was smaller in females compared with males [56]; cold decreased the fatigue index of a sustained 2-min maximal voluntary contraction in males but not in females [57]; a significant benefit of temperature reduction in hypoxia ischemia was found in females but not in males [58]. 
In our study, sex differences of brains were found in the young adult residents at HA, which could be different from that in children or older peoples, as age-associated changes are sex-specific. A study has shown that men experienced greater volume decrement across age-groups than women, particularly in the dorsolateral prefrontal regions [59]. Another MRI studied on healthy adults aged range 18-80 years showed that the greatest amount of atrophy in elderly men was in the left hemisphere, whereas in women age effects were symmetric [60].

The limitation in our study is that the inter-ethnic differences in brain structures can be large. We cannot draw a conclusion that gene and developmental environment which one dominantly determined the different pattern of sex differences between Tibetan and Han brains. Brain morphological differences between populations of different origins have been found in early neonate life [61] and in adults in terms of whole brain and region-specific volume [62-64]. Our previous study has revealed that, compared with Han subjects living at lowlands, Tibetans living on the Qinghai-Tibetan Plateau were associated with structural modifications in cortical thicknesses, curvature, and sulcus [39]. Therefore, the global brain differences between these two populations may underlie the different pattern of sex differences between Tibetan and Han brains. The another limitation of this study is that we did not conduct neuropsychiatric tests in Han subjects, and thus cannot compare the neuropsychiatric ability between Tibetans and Han subjects.

In our study, females showed significant decreases of GM volume in the left pars opercularis and pars triangularis of Broca's area, and GM volume in the left pars opercularis in Tibetans had a significant positive correlation with forward digit span performance. Previous study has found an association between impaired forward digit span performance and ischemia in pars opercularis [65]. Moreover, stimulation of left Broca's area interfered with digit span, producing significantly more item than order errors [66]. Forward digit span is a kind of verbal phonological short-term memory. MRI studies on articulatory suppression indicated that pars opercularis was involved in phonological short term-memory $[67,68]$. Patients, who had a disability to make phonological judgements, showed lesions in the left Broca's area [69]. Therefore, the decreased GM volume of left pars opercularis of Broca area may be associated with poor phonological short term-memory in Tibetan females.

\section{Conclusions}

In agreement with Han and other population Tibetan males have larger brains than females. Female brains have a larger proportion of GM than males in Tibetans but not in Han subjects. Moreover, sex differences in brain volume and cortical thickness in Tibetans showed a distinct pattern with that in Han subjects. Our results support the hypothesis that females had a better capacity to adapt to hypoxia. In Tibetans, female brain developments seem to be more susceptible to HA environmental factors. Sex differences of regional Tibetan brain volumes may be related to different neuropsychiatric performances in the two sexes.

\section{Abbreviations}


HA: high-altitude; GM: gray matter; CT: cortical thickness; WM: white matter; ROCF: Rey-Osterrieth Complex Figure.

\section{Declarations}

Ethics approval and consent to participate

The experimental protocol was approved by the Research Ethics Review Board of Xiamen University.

\section{Consent for publication}

Not applicable.

\section{Availability of data and material}

Presented in the main manuscript.

\section{Competing interests}

The authors declare that they have no competing interests.

\section{Funding}

This study was supported by the National Natural Science Foundation of China $(81871519 ; 81471630)$.

\section{Authors' contributions}

JZ conceived of the research question, CF and JZ designed the study and created experimental protocols, $\mathrm{CF}, \mathrm{CZ}, \mathrm{YZ}, \mathrm{WY}, \mathrm{JL}$ and collected the data, CF and CZ analyzed the data, JZ wrote the manuscript. All authors read and approved the final manuscript.

\section{Acknowledgements}

Not applicable. 


\section{Authors' information}

${ }^{1}$ Institute of Brain Diseases and Cognition, Medical College of Xiamen University, Xiamen, Fujian, China.

${ }^{2}$ Medical College of Xizang University, Lasa, Tibet Autonomous Region, China. ${ }^{3}$ Institute of high altitude medicine, Tibet Autonomous Region People's Hospital, Lasa, Tibet Autonomous Region, China.

${ }^{4}$ Department of Radiology, Tibet Autonomous Region People's Hospital, Lasa, Tibet Autonomous Region, China. ${ }^{5}$ Magnetic Resonance Center, Zhongshan Hospital Xiamen University, Xiamen, China. ${ }^{6}$ Institute for Brain Research and Rehabilitation, South China Normal University, Guangzhou, China

\section{References}

1. Soliz J, Thomsen JJ, Soulage C, Lundby C, Gassmann M. Sex-dependent regulation of hypoxic ventilation in mice and humans is mediated by erythropoietin. Am J Physiol Regul Integr Physiol. 2009;296(6):R1837-46.

2. Wu T, Wang X, Wei C, Cheng H, Wang X, Li Y, Ge-Dong, Zhao H, Young P, Li G, et Hemoglobin levels in Qinghai-Tibet: different effects of gender for Tibetans vs. Han. J Appl Physiol (1985).2005;98(2):598-604.

3. Lombardi C, Meriggi P, Agostoni P, Faini A, Bilo G1, Revera M, Caldara G, Di Rienzo M, Castiglioni P, Maurizio $B$, et al. High-altitude hypoxia and periodic breathing during sleep: gender-related differences. J Sleep Res. 2013;22(3):322-30.

4. Caravita S, Faini A, Lombardi C, Valentini M, Gregorini F, Rossi J, Meriggi P, Di Rienzo M, Bilo G, Agostoni $\mathrm{P}$, et al. Sex and acetazolamide effects on chemoreflex and periodic breathing during sleep at altitude. Chest. 2015;147(1):120-31.

5. Zaccagni L, Barbieri D, Cogo A, Gualdi-Russo E. Anthropometric and body composition changes during expeditions at high altitude. High Alt Med Biol. 2014;15(2):176-82.

6. Silva-Urra JA, Núñez-Espinosa CA, Niño-Mendez OA, Gaitán-Peñas H, Altavilla C, Toro-Salinas A, Torrella JR, Pagès T, Javierre CF, Behn $\mathrm{C}$, et al. Circadian and Sex Differences After Acute HighAltitude Exposure: Are Early AcclimationResponses Improved by Blue Light? Wilderness Environ Med. 2015;26(4):459-71.

7. Maclnnis MJ, Carter EA, Freeman MG, Pandit BP, Siwakoti A, Subedi A, Timalsina U, Widmer N, Thapa GB, Koehle MS, Rupert JL. A prospective epidemiological study of acute mountain sickness in Nepalese pilgrims ascending to high altitude (4380 m). PLoS One. 2013;8(10):e75644.

8. Negi PC, Asotra S, V RK, Marwah R, Kandoria A, Ganju NK, Sharma R, Bhardwaj R. Epidemiological study of chronic mountain sickness in natives of Spiti Valley in the GreaterHimalayas. High Alt Med Biol. 2013;14(3):220-9.

9. Basnyat B. High altitude pilgrimage medicine. High Alt Med Biol. 2014;15(4):434-9. 
10. Dalla C, Pitychoutis PM, Kokras N, Papadopoulou-Daifoti Z. Sex differences in response to stress and expression of depressive-like behaviours in the rat. Curr Top Behav Neurosci. 2011;8:97-118.

11. Ngun TC, Ghahramani N, Sánchez FJ, Bocklandt S, Vilain E. The genetics of sex differences in brain and behavior. Front Neuroendocrinol. 2011;32(2):227-46.

12. Kret ME, De Gelder B. A review on sex differences in processing emotional signals. Neuropsychologia. 2012;50(7):1211-21.

13. Kumar AJ, Takada SH, Motta-Teixeira LC, Lee VY, Xavier GF, Nogueira MI. Sex differences in somatic and sensory motor development after neonatal anoxia in Wistar rats. Behav Brain Res. 2017;333:242-50.

14. Netto CA, Sanches E, Odorcyk FK, Duran-Carabali LE, Weis SN. Sex-dependent consequences of neonatal brain hypoxia-ischemia in the rat. J Neurosci Res. 2017;95(1-2):409-21.

15. Sukhanova IA, Sebentsova EA, Khukhareva DD, Manchenko DM, Glazova NY, Vishnyakova PA, Inozemtseva LS, Dolotov OV, Vysokikh MY, Levitskaya NG. Gender-dependent changes in physical development, BDNF content and GSH redox system in a model of acute neonatal hypoxia in rats. Behav Brain Res. 2018;350:87-98.

16. Liu J, Liu Y, Ren LH, Li L, Wang Z, Liu SS, Li SZ, Cao TS. Effects of race and sex on cerebral hemodynamics, oxygen delivery and blood flow distribution in response to high altitude. Sci Rep. 2016;6:30500.

17. Chen L, Cai C, Yang T, Lin J, Cai S, Zhang J, Chen Z. Changes in brain iron concentration after exposure to high-altitude hypoxia measured by quantitative susceptibility mapping. Neuroimage. 2017;147:488-99.

18. Macey PM, Prasad JP, Ogren JA, Moiyadi AS, Aysola RS, Kumar R, Yan-Go FL, Woo MA, Albert Thomas M, Harper RM. Sex-specific hippocampus volume changes in obstructive sleep apnea. Neuroimage Clin. 2018;20:305-17.

19. Smith AL, Alexander M, Rosenkrantz TS, Sadek ML, Fitch RH. Sex differences in behavioral outcome following neonatal hypoxia ischemia: insights from a clinical meta-analysis and a rodent model of induced hypoxic ischemic brain injury. Exp Neurol. 2014;254:54-67.

20. Kanekar S, Bogdanova OV, Olson PR, Sung YH, D'Anci KE, Renshaw PF. Hypobaric hypoxia induces depression-like behavior in female Sprague-Dawley rats, but not in males. High Alt Med Biol. 2015;16(1):52-60.

21. Sheth C, Ombach H, Olson P, Renshaw PF, Kanekar S. Increased Anxiety and Anhedonia in Female Rats Following Exposure to Altitude. High Alt Med Biol. 2018;19(1):81-90.

22. Arteni NS, Pereira LO, Rodrigues AL, Lavinsky D, Achaval ME, Netto CA. Lateralized and sexdependent behavioral and morphological effects of unilateral neonatalcerebral hypoxia-ischemia in the rat. Behav Brain Res. 2010;210(1):92-8.

23. Donders J, Hoffman NM. Gender differences in learning and memory after pediatric traumatic brain injury. Neuropsychology. 2002;16(4):491-9. 
24. Morrison WE, Arbelaez JJ, Fackler JC, De Maio A, Paidas CN. Gender and age effects on outcome after pediatric traumatic brain injury. Pediatr Crit Care Med. 2004;5(2):145-51.

25. Bona E, Hagberg H, Løberg EM, Bågenholm R, Thoresen M. Protective effects of moderate hypothermia after neonatal hypoxia-ischemia: short- and long-termoutcome. Pediatr Res. 1998;43(6):738-45.

26. Hagberg $H$, Wilson MA, Matsushita H, Zhu C, Lange M, Gustavsson M, Poitras MF, Dawson TM, Dawson VL, Northington F, Johnston MV. PARP-1 gene disruption in mice preferentially protects males from perinatal brain injury. J Neurochem. 2004;90(5):1068-1075.

27. Renolleau S, Fau S, Charriaut-Marlangue C. Gender-related differences in apoptotic pathways after neonatal cerebral ischemia. Neuroscientist. 2008;14(1):46-52.

28. Ruigrok AN, Salimi-Khorshidi G, Lai MC, Baron-Cohen S, Lombardo MV, Tait RJ, Suckling J. A metaanalysis of sex differences in human brain structure. Neurosci Biobehav Rev. 2014;39:34-50.

29. Gur RC, Turetsky BI, Matsui M, Yan M, Bilker W, Hughett P, Gur RE. Sex differences in brain gray and white matter in healthy young adults: correlations with cognitive performance. J Neurosci. 1999;19(10):4065-72.

30. Luders E, Toga A W. Sex differences in brain anatomy. Prog in Brain Res. 2010;186(1):3.

31. Sacher J, Neumann J, Okon-Singer H, Gotowiec S, Villringer A. Sexual dimorphism in the human brain: evidence from neuroimaging. Magn Reson Imaging. 2013;31(3):366-75.

32. Im K, Lee JM, Lee J, Shin YW, Kim IY, Kwon JS, Kim SI. Gender difference analysis of cortical thickness in healthy young adults with surface-basedmethods. Neuroimage. 2006;31(1):31-8.

33. Sowell ER, Peterson BS, Kan E, Woods RP, Yoshii J, Bansal R, Xu D, Zhu H, Thompson PM, Toga AW. Sex differences in cortical thickness mapped in 176 healthy individuals between 7 and 87 years of age. Cereb Cortex. 2007;17(7):1550-60.

34. Luders E, Gaser C, Narr KL, Toga AW. Why sex matters: brain size independent differences in gray matter distributions between men and women. J Neurosci. 2009 Nov 11;29(45):14265-70.

35. Gautam P, Cherbuin N, Sachdev PS, Wen W, Anstey KJ. Sex differences in cortical thickness in middle aged and early old-aged adults: Personality and Total Health Through Life study. Neuroradiology. 2013;55(6):697-707.

36. Luders E, Narr KL, Thompson PM, Rex DE, Woods RP, Deluca H, Jancke L, Toga AW. Gender effects on cortical thickness and the influence of scaling. Hum Brain Mapp. 2006;27(4):314-24.

37. Feis DL, Brodersen KH, von Cramon DY, Luders E, Tittgemeyer M. Decoding gender dimorphism of the human brain using multimodal anatomical and diffusion MRI data. Neuroimage. 2013;70:250-7.

38. Brun CC, Leporé N, Luders E, Chou YY, Madsen SK, Toga AW, Thompson PM. Sex differences in brain structure in auditory and cingulate regions. Neuroreport. 2009;20(10):930-5.

39. Wei W, Wang X, Gong Q, Fan M, Zhang J. Cortical Thickness of Native Tibetans in the QinghaiTibetan Plateau. AJNR Am J Neuroradiol. 2017;38(3):553-60. 
40. Baum DM, Saussereau M, Jeton F, Planes C, Voituron N, Cardot P, Fiamma MN, Bodineau L. Effect of Gender on Chronic Intermittent Hypoxic Fosb Expression in Cardiorespiratory-RelatedBrain Structures in Mice. Front Physiol. 2018;9:788.

41. Pequignot JM, Spielvogel H, Caceres E, Rodriguez A, Semporé B, Pequignot J, Favier R. Influence of gender and endogenous sex steroids on catecholaminergic structures involved in physiological adaptation to hypoxia. Pflugers Arch. 1997;433(5):580-6.

42. Hill CA, Fitch RH. Sex differences in mechanisms and outcome of neonatal hypoxia-ischemia in rodent models: implications for sex-specific neuroprotection in clinical neonatal practice. Neurol Res Int. 2012:867531.

43. Charriaut-Marlangue C, Besson VC, Baud O. Sexually Dimorphic Outcomes after Neonatal Stroke and Hypoxia-Ischemia. Int J Mol Sci. 2017;19(1).

44. Mage DT, Donner M. Female resistance to hypoxia: does it explain the sex difference in mortality rates? J Womens Health (Larchmt). 2006;15(6):786-94.

45. Gonzales GF, Góñez C, Villena A. Adrenopause or decline of serum adrenal androgens with age in women living at sea level or at high altitude. J Endocrinol. 2002;173(1):95-101.

46. Payan HM, Conrad JR. Carotid ligation in gerbils. Influence of age, sex, and gonads. Stroke. 1977;8(2):194-6.

47. Hurn PD, Macrae IM. Estrogen as a neuroprotectant in stroke. J Cereb Blood Flow Metab. 2000;20(4):631-52.

48. Guo JM, Shu H, Wang L, Xu JJ, Niu XC, Zhang L. SIRT1-dependent AMPK pathway in the protection of estrogen against ischemic brain injury. CNS Neurosci Ther. 2017;23(4):360-9.

49. Hall ED, Pazara KE, Linseman KL. Sex differences in postischemic neuronal necrosis in gerbils. J Cereb Blood Flow Metab. 1991;11(2):292-8.

50. Hurn PD, Littleton-Kearney MT, Kirsch JR, Dharmarajan AM, Traystman RJ. Postischemic cerebral blood flow recovery in the female: effect of 17 beta-estradiol. J Cereb Blood Flow Metab. 1995;15(4):666-72.

51. Resnick SM, Maki PM, Golski S, Kraut MA, Zonderman AB. Effects of estrogen replacement therapy on PET cerebral blood flow and neuropsychological performance. Horm Behav. 1998;34(2):171-82.

52. Maki PM, Resnick SM. Longitudinal effects of estrogen replacement therapy on PET cerebral blood flow and cognition. Neurobiol Aging. 2000;21(2):373-83.

53. Shamma FN, Fayad P, Brass L, Sarrel P. Middle cerebral artery blood velocity during controlled ovarian hyperstimulation. Fertil Steril. 1992;57(5):1022-5.

54. Devous MD Sr, Stokely EM, Chehabi HH, Bonte FJ. Normal distribution of regional cerebral blood flow measured by dynamic single-photon emission tomography. J Cereb Blood Flow Metab. 1986;6(1):95104.

55. Li ZJ, Matsuda H, Asada T, Ohnishi T, Kanetaka H, Imabayashi E, Tanaka F. Gender difference in brain perfusion 99mTc-ECD SPECT in aged healthy volunteers aftercorrection for partial volume 
effects. Nucl Med Commun. 2004;25(10):999-1005.

56. Sato F, Matsushita S, Hyodo K, Akishima S, Imazuru T, Tokunaga C, Enomoto Y, Kanemoto S, Hiramatsu Y, Sakakibara Y. Sex difference in peripheral arterial response to cold exposure. Circ J. 2008;72(8):1367-72.

57. Solianik R, Skurvydas A, Pukènas K, Brazaitis M. Comparison of the effects of whole-body cooling during fatiguing exercise in males and females. Cryobiology. 2015;71(1):112-8.

58. Smith AL, Garbus H, Rosenkrantz TS, Fitch RH. Sex differences in behavioral outcomes following temperature modulation during inducedneonatal hypoxic ischemic injury in rats. Brain Sci. 2015;5(2):220-40.

59. Gur RC, Gunning-Dixon FM, Turetsky BI, Bilker WB, Gur RE. Brain region and sex differences in age association with brain volume: a quantitative MRI study of healthy young adults. Am J Geriatr Psychiatry. 2002;10(1):72-80.

60. Gur RC, Mozley PD, Resnick SM, Gottlieb GL, Kohn M, Zimmerman R, Herman G, Atlas S, Grossman R, Berretta $D$, et al. Gender differences in age effect on brain atrophy measured by magnetic resonance imaging. Proc Natl Acad Sci U S A. 1991;88(7):2845-9.

61. Bai J, Abdul-Rahman MF, Rifkin-Graboi A, Chong YS, Kwek K, Saw SM, Godfrey KM, Gluckman PD, Fortier MV, Meaney MJ, et al. Population differences in brain morphology and microstructure among Chinese, Malay, and Indianneonates. PLoS One. 2012;7(10):e47816.

62. Vadakkumpadan F, Tong Y, Sun Y. Statistical analysis of morphological differences between brains. Int J Neurosci. 2006;116(4):407-18.

63. Isamah N, Faison W, Payne ME, MacFall J, Steffens DC, Beyer JL, Krishnan KR, Taylor WD. Variability in frontotemporal brain structure: the importance of recruitment of African Americans in neuroscience research. PLoS One. 2010;5(10):e13642.

64. Tang Y, Hojatkashani C, Dinov ID, Sun B, Fan L, Lin X, Qi H, Hua X, Liu S, Toga AW. The construction of a Chinese MRI brain atlas: a morphometric comparison study between Chinese and Caucasian cohorts. Neuroimage. 2010;51(1):33-41.

65. Newhart M, Trupe LA, Gomez Y, Cloutman L, Molitoris JJ, Davis C, Leigh R, Gottesman RF, Race D, Hillis AE. Asyntactic comprehension, working memory, and acute ischemia in Broca's area versus angulargyrus. Cortex. 2012;48(10):1288-97.

66. Papagno C, Comi A, Riva M, Bizzi A, Vernice M, Casarotti A, Fava E, Bello L. Mapping the brain network of the phonological loop. Hum Brain Mapp. 2017;38(6):3011-24.

67. Paulesu E, Frith CD, Frackowiak RS. The neural correlates of the verbal component of working memory. Nature. 1993;362(6418):342-5.

68. Rogalsky C, Matchin W, Hickok G. Broca's area, sentence comprehension, and working memory: an fMRI Study. Front Hum Neurosci. 2008;2:14.

69. Vallar G, Di Betta AM, Silveri MC. The phonological short-term store-rehearsal system: patterns of impairment and neural correlates. Neuropsychologia. 1997;35(6):795-812. 
70. Zhang J, Liu H, Yan X, Weng X. Minimal effects on human memory following long-term living at moderate altitude. High Alt Med Biol. 2011;12(1):37-43.

71. Joyner AH, J CR, Bloss CS, Bakken TE, Rimol LM, Melle I, Agartz I, Djurovic S, Topol EJ, Schork NJ, et al. A common MECP2 haplotype associates with reduced cortical surface area in humans in twoindependent populations. Proc Natl Acad Sci U S A. 2009;106(36):15483-8.

72. Palaniyappan L, Mallikarjun P, Joseph V, White TP, Liddle PF. Regional contraction of brain surface area involves three large-scale networks in schizophrenia. Schizophr Res. 2011;129(2-3):163-8.

\section{Tables}

Table 1 Demographic information of Tibetan males and females

\begin{tabular}{llll}
\hline & Males & Females & $p$ \\
\hline Sample size & 61 & 68 & - \\
Age (years) (mean \pm SD) & $20.0 \pm 1.1$ & $19.8 \pm 0.9$ & 0.083 \\
Education (years) (mean \pm SD) & $12.8 \pm 0.5$ & $12.7 \pm 0.5$ & 0.183 \\
Body Mass Index (mean \pm SD) & $19.5 \pm 2.1$ & $20.1 \pm 2.0$ & 0.185 \\
Altitudes (m) (mean \pm SD) & $4040.9 \pm 374.4$ & $3943.2 \pm 275.2$ & 0.087 \\
Buddhists (\%) & 95.1 & 94.1 & - \\
Smokers and alcoholics & None & None & - \\
\hline
\end{tabular}

Table 2 Neuropsychiatric characteristics of Tibetan males and females 


\begin{tabular}{|c|c|c|c|}
\hline Tests & Males & Females & $p$ \\
\hline \multicolumn{4}{|l|}{ Mental control } \\
\hline Digit serial accumulation & $8.1 \pm 3.0$ & $7.1 \pm 2.9$ & 0.029 \\
\hline Backward task & $11.5 \pm 1.3$ & $11.6 \pm 1.9$ & 0.330 \\
\hline Accumulation & $11.1 \pm 1.8$ & $10.7 \pm 1.5$ & 0.094 \\
\hline Figural memory & $10.9 \pm 1.7$ & $10.7 \pm 1.5$ & 0.228 \\
\hline Visual recognition & $10.4 \pm 2.3$ & $10.5 \pm 2.1$ & 0.419 \\
\hline Visual reproduction & $11.4 \pm 1.4$ & $11.1 \pm 1.3$ & 0.128 \\
\hline Touch & $12.2 \pm 3.1$ & $11.4 \pm 2.2$ & 0.055 \\
\hline Digit span Forward task & $13.6 \pm 2.3$ & $12.7 \pm 2.4$ & 0.027 \\
\hline \multicolumn{4}{|c|}{ Rey-Osterrieth Complex Figure test } \\
\hline Immediate recall & $25.3 \pm 6.7$ & $24.5 \pm 6.0$ & 0.251 \\
\hline Delayed recall & $25.9 \pm 6.2$ & $24.6 \pm 6.8$ & 0.141 \\
\hline Beck Anxiety Inventory score & $29.3 \pm 6.8$ & $30.3 \pm 7.1$ & 0.209 \\
\hline
\end{tabular}

\section{Figures}




\section{Tibetan}

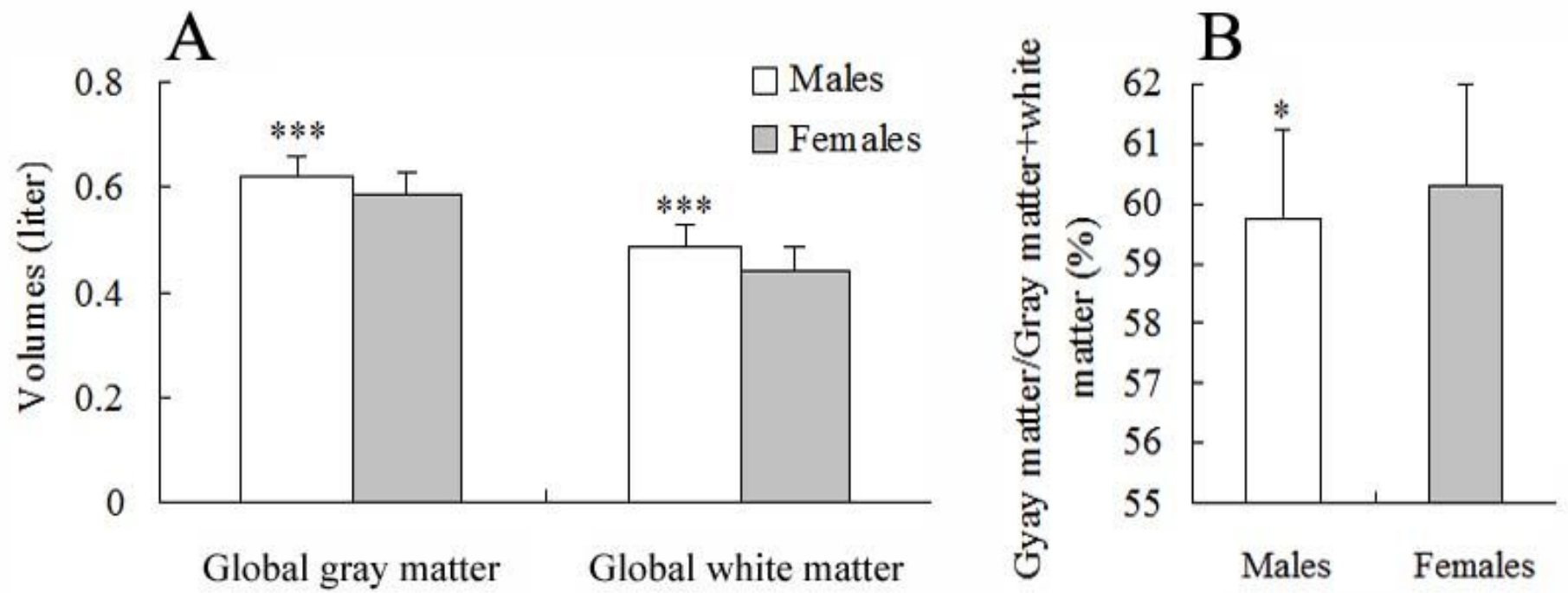

\section{Han}
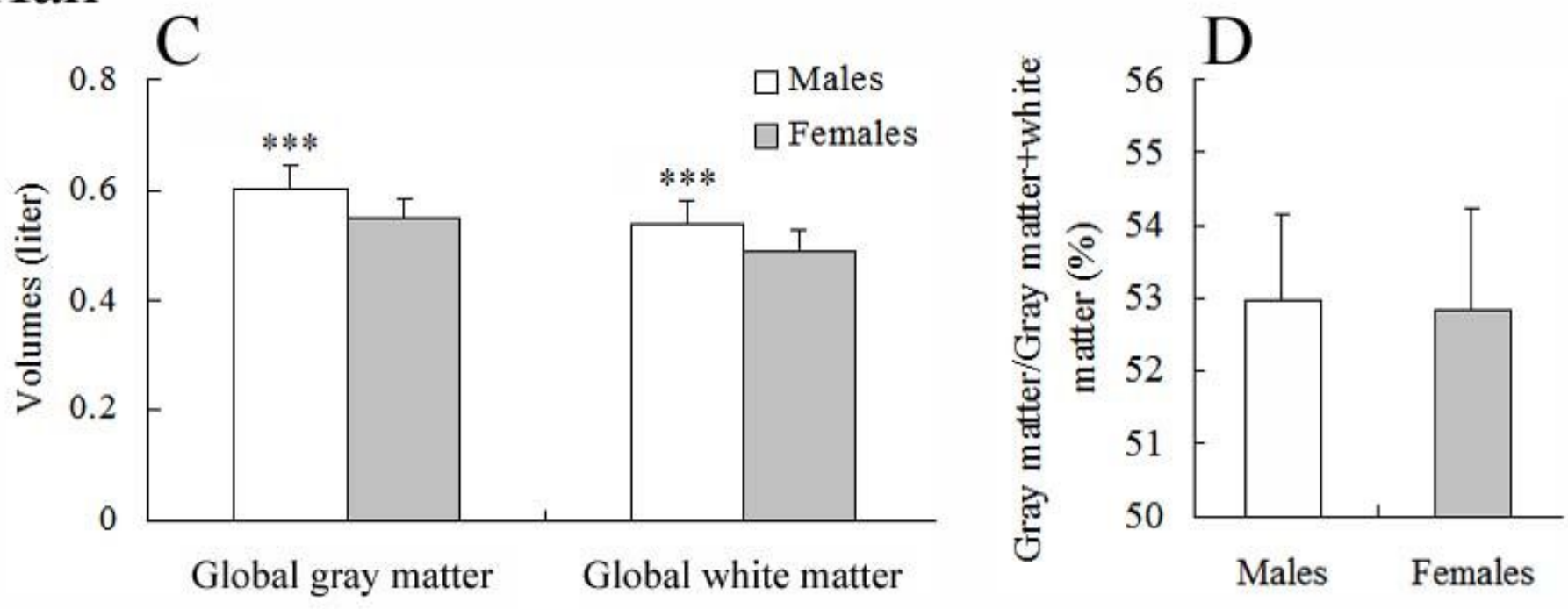

Figure 1

(A) Sex differences in brain volumes. Global brain volumes and percentage of gray matter/gray matter + white matter in Tibetans ( $A$ and $B$ ) and in Han population ( $C$ and $D) .{ }^{*}, p<0.05 ; * \star *, p<0.001$. 


\section{Cortical gray matter volume}

left

Tibetan

females $<$ males right

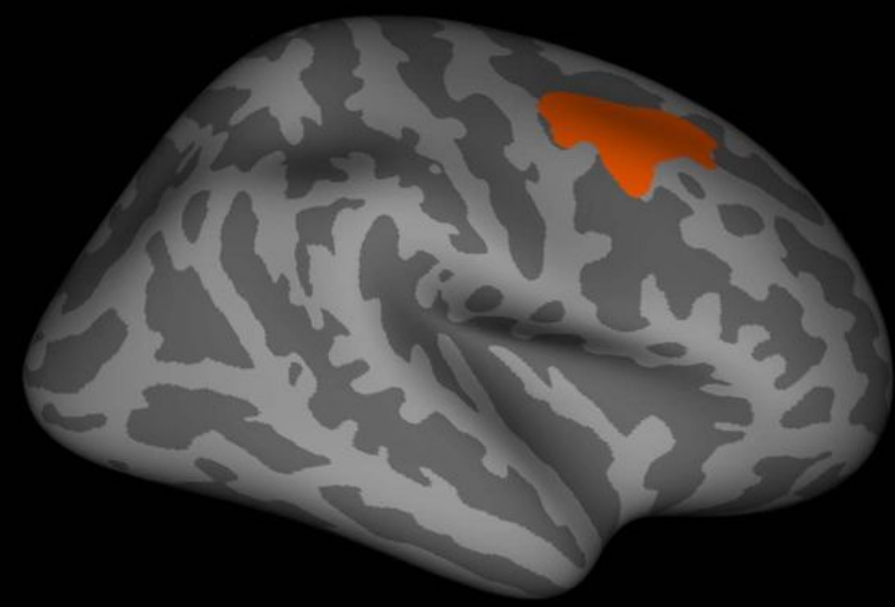

\section{Han \\ females $>$ males}

\section{Figure 2}

Colored regions showing significant sex differences of cortical gray matter volume. 


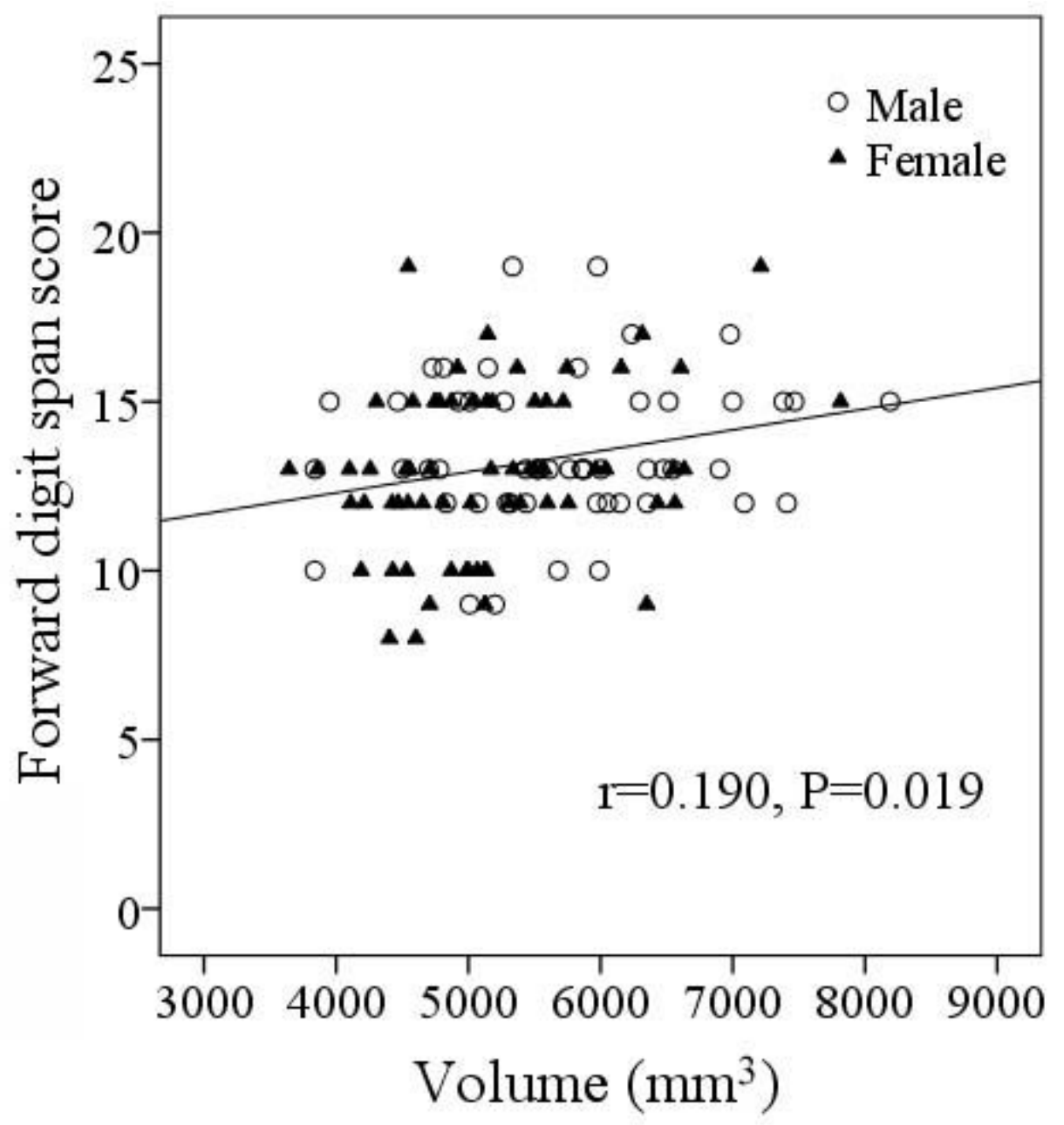

Figure 3

Correlation between gray matter volume in the left pars opercularis and forward digit span performance in Tibetan males and females. 


\section{Cortical thickness}

\section{Tibetan left right}

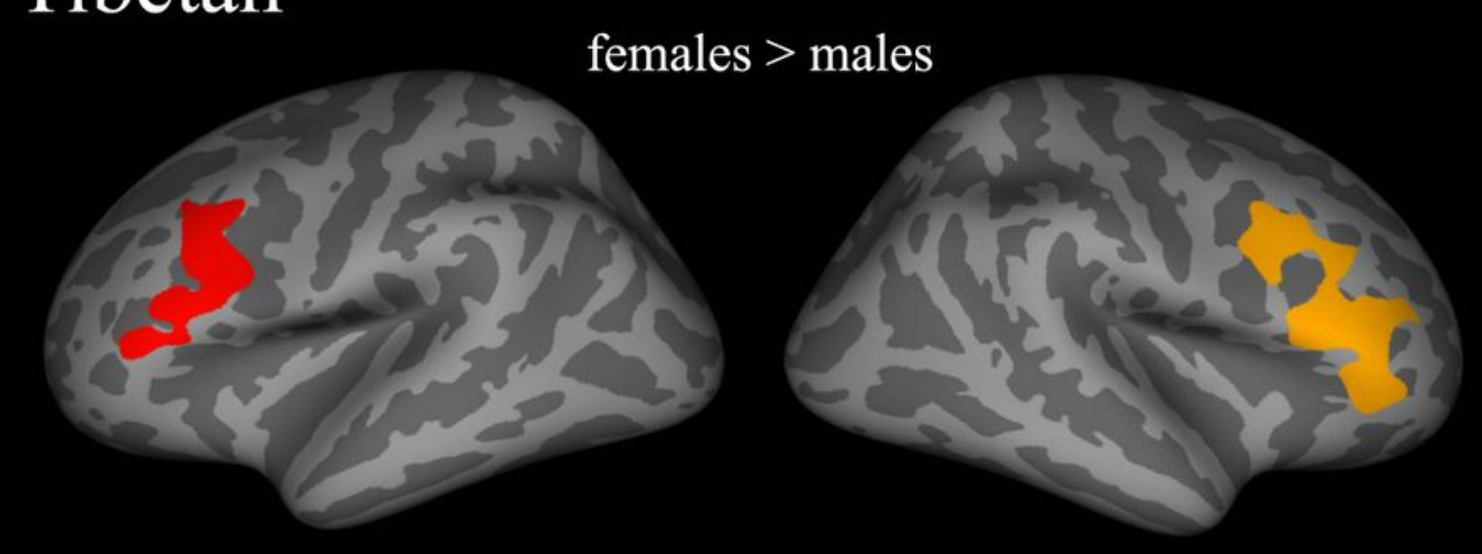

\section{Han}

females $>$ males

\section{Figure 4}

Colored regions showing higher cortical thickness in females than males. 

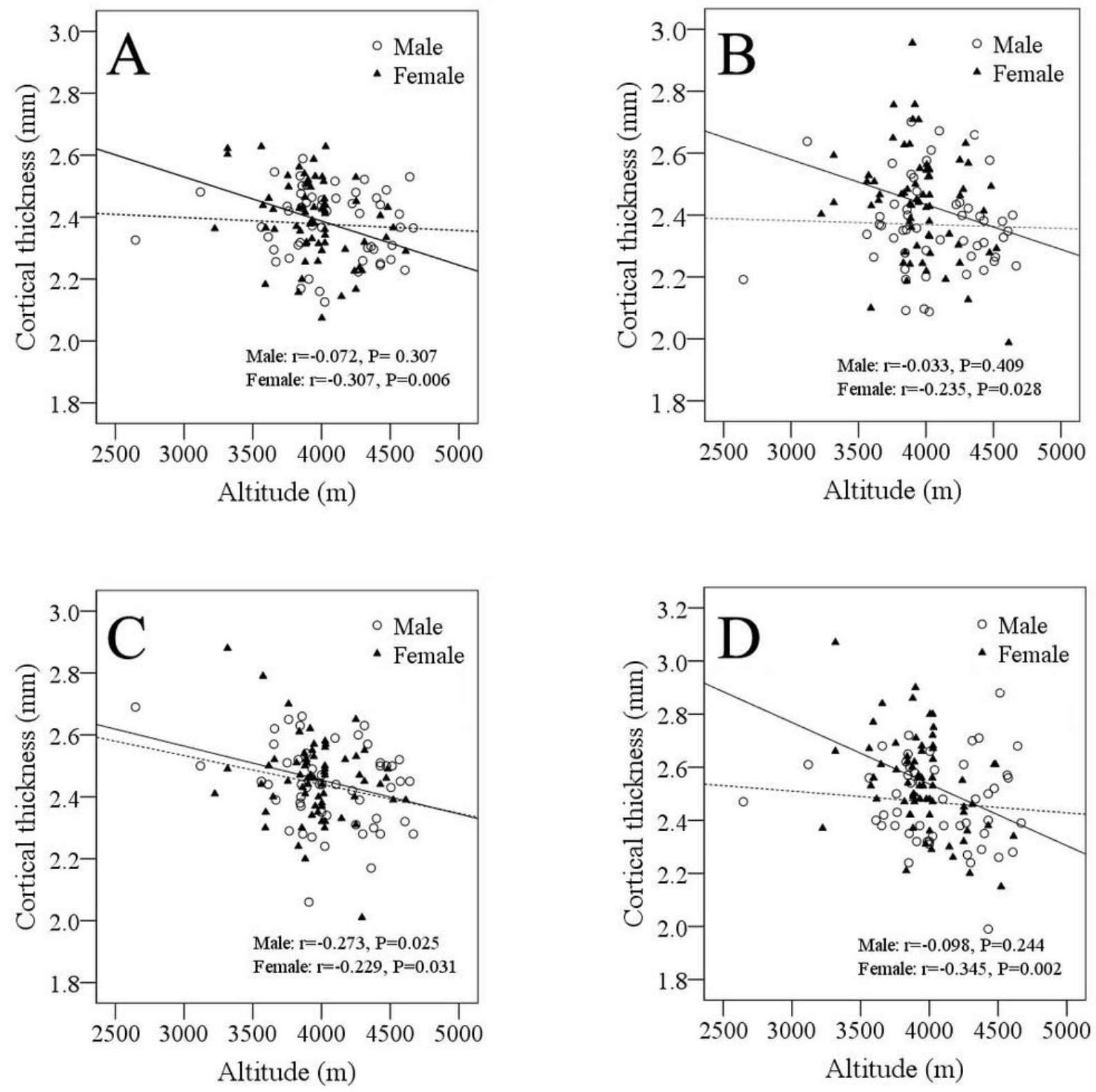

Figure 5

Correlations of cortical thickness values with altitude in Tibetan males and females. (A) left rostral middle frontal gyrus; (B) left pars triangularis; (C) right rostral middle frontal gyrus; (D) right pars triangularis. 


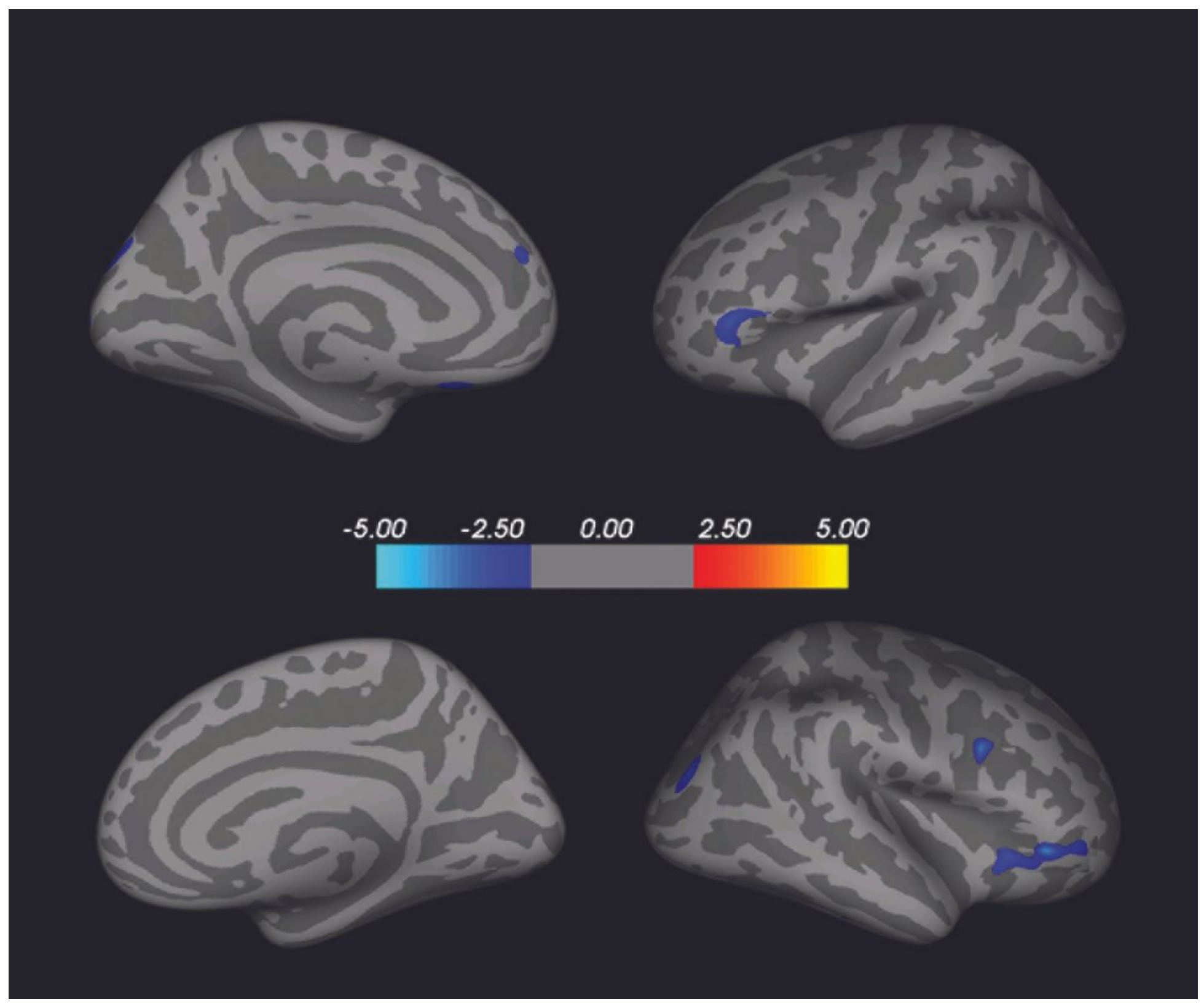

\section{Figure 6}

Global correlations of cortical thickness values with altitude in Tibetan females. Blue indicates significant negative correlation. 